Anna Mikołajewska*

\section{Literacki dyskurs pamięci o I wojnie światowej}

DOI: http://dx.doi.org/10.12775/LC.2018.042

Maria Gierlak/Małgorzata Klentak-Zablocka/ Thorsten Unger (Hrsg.

\section{Literarische Erinnerung an den Ersten Weltkrieg in Regionen Mitteleuropas}

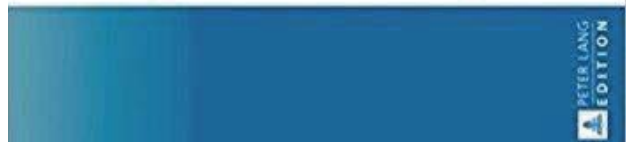

roku 2017 ukazała się monografia LiterarischeErinnerungandenErsten Weltkrieg in Regionen Mitteleuropas pod redakcją germanistów Marii Gierlak i Małgorzaty Klentak-Zabłockiej z Uniwersytetu Mikołaja Kopernika w Toruniu oraz Thorstena Ungera $\mathrm{z}$ Uniwersytetu Ottona von Guerickego w Magdeburgu. Publikacja

* Adiunkt w Katedrze Filologii Germańskiej Uniwersytetu Mikołaja Kopernika w Toruniu. E-mail: nanett@umk.pl. jest owocem wymiany myśli zainicjowanej w fazie przygotowań do konferencji Der Erste Weltkrieg im kulturellen Gedächtnis Europas. Regionale und globale Dimensionen / / I wojna światowa $w$ pamięci kulturowej $w$ Europie. Aspekty regionalne i globalne $\mathrm{i}$ kontynuowanej w czasie obrad w Toruniu 1-4 października 2014 roku. Omawiany tom jest już dziewiątym w serii „Warschauer Studien zur Kultur- und Literaturwissenschaft”, ukazującej się pod redakcją Karola Sauerlanda w wydawnictwie Peter Lang. „Warschauer Studien” są skierowane przede wszystkim do filologów, a za cel stawiają sobie popularyzowanie badań dotyczących Europy Środkowo-Wschodniej. Teksty zamieszczone w omawianej publikacji dobrze wpisują się w założenia wspomnianej serii wydawniczej, skupiając się na teatrze działań wojennych pozostającym dotąd nierzadko na marginesie badań dotyczących Wielkiej Wojny i proponując nań spojrzenie wykraczające poza historię wojskowości, elit i wielkich ludzi.

Przyjęta w książce perspektywa badawcza I wojny światowej to perspektywa filologa, co niesie za sobą liczne korzyści. Po części pozwala ustrzec się przed upolitycznieniem badań i ich swoistym uproszczeniem nakierowanym na odbiór przez szeroko rozumianą opinię publiczną, które uwidoczniło się w latach poprzedzających jubileusz wybuchu Wielkiej Wojny w Wielkiej Brytanii i we Francji. Skierowanie uwagi na historię regionalną, wojenne doświadczenia jednostek i literackie reakcje na koszmar wojny masowej sprawia, że historia nie daje się łatwo zawłaszczyć przez dyskusje polityczne skoncentrowane na poszukiwaniu winnych, gloryfikowaniu bohaterów i apelach pamięci. Taka perspektywa w badaniach jest poniekąd wpisana w wojenne doświadczenie i pamięć o I wojnie w Europie Wschodniej, gdzie, jak słusznie zauważają Włodzimierz Borodziej i Maciej Górny, z jednej strony 
narodowość poległych pozostaje kwestią sporną, a próby wpisania żołnierzy walczących we wrogich armiach w poczet bohaterów „sprawy polskiej” nastręczają trudności (Borodziej i Górny 2015: 132; por. Mick 2010: 317), z drugiej - już stan „wiedzy o przebiegu i skutkach I wojny światowej” (Borodziej i Górny 2015: 132) jest „skutkiem, a po części przyczyną długoletnich zaniedbań [...] historyków" (ibid.). Wszystko to sprawiło, że przez lata w świadomości opinii publicznej (a poniekąd także badaczy) I wojna pozostawała w cieniu II wojny światowej, a prace jej poświęcone koncentrowały się przede wszystkim na sytuacji na froncie zachodnim.

Zmiana paradygmatu jest widoczna w ostatnich latach zarówno w historiografii polskiej, jak i niemieckiej (czy ogólnie zachodnioeuropejskiej). Wielka Wojna jako efekt działań wielkich ludzi oraz przebieg kampanii wojennych zeszły na dalszy plan, a ich miejsce zajęly losy zwykłych żołnierzy prezentowanych coraz częściej jako ofiary niezależnie od zajmowanej przez nich strony konfliktu. Wiąże się to $\mathrm{z}$ dowartościowaniem źródel, takich jak listy, pamiętniki i dzienniki, w których „zwykli” ludzie dochodzą do głosu, czego wyrazem jest m.in. książka Die Deutschen an der Somme 1914-1918 pod redakcją Gerharda Hirschfelda, Gerda Krumeicha i Iriny Renz (2006). Zaprezentowane w niej dokumenty ze zbiorów Bibliothek für Zeitgeschichte w Stuttgarcie opisują nie tylko doświadczenia wojenne niemieckich żołnierzy, ale także wspomnienia francuskiej ludności cywilnej. Wymusza to niejako rozpatrywanie I wojny nie tylko jako operacji wojennej, ale także jako konfliktu dotkliwie odbijającego się na cywilach. Takie podejście pozwala przede wszystkim na ukazanie wojny w szerszym kontekście pracy przymusowej, deportacji ludności i strachu przed wrogiem prowadzącego do planowego prześladowa- nia ludności cywilnej, tematów podejmowanych już przez Johna Horne’a i Alana Kramera w pracy Deutsche Kriegsgreuel $(2001)^{1}$, a zdających się dotąd tematami zarezerwowanymi dla badań nad II wojną światową. Warto przy tym nadmienić, że Horn i Kramer zdecydowali się sięgnąć do egodokumentów autorstwa niemieckich żołnierzy $\mathrm{w}$ zastępstwie niedostępnych, bo zniszczonych w czasie II wojny światowej akt sztabu generalnego i armii pruskiej. Zapewne to bariera językowa kazała zachodnim historykom wierzyć przez lata, że na wschodzie podobne egodokumenty nie zachowały się. Wyjście $\mathrm{w}$ badaniach poza front zachodni i fakt, iż historiografia wschodnioeuropejska mówi coraz głośniej i coraz częściej w językach zachodnich państw Europy, sprawiają, że tezy, takie jak te prezentowane przez prominentnego brytyjskiego historyka Johna Keegana, odchodzą powoli do lamusa. Jeszcze w 1999 roku Keegan forsował tezę o braku egodokumentów opisujących walki na froncie wschodnim, których autorami mogliby być żołnierze monarchii austro-węgierskiej i carskiej Rosji (Keegan 1999: 161; reakcja na sądy Keegana zob. m.in. Pollmann 2013: 88). Obecność historyków Europy Środkowej i Wschodniej w projektach takich jak 1914-1918 online: International Encyclopedia of the First World War (http://www.1914-1918-online.net) daje nadzieję na zaistnienie Europy Środkowo-Wschodniej na mapie badań nad I wojną światową, ale na jej stałą obecność w całościowych opracowaniach dotyczących tego konfliktu trzeba będzie jeszcze poczekać. Sceptycznie odnoszą się do tej kwestii Włodzimierz Borodziej

1 Książka Johna Horne'a i Alana Kramera German Atrocities 1914. A History of Denial (New Haven: Yale University Press) ukazała się $\mathrm{w}$ języku angielskim w 2001 roku, ale to w Niemczech po wydaniu w języku niemieckim stała się przedmiotem szczególnie ożywionej dyskusji. 
i Maciej Górny (2015: 135), przywołując jako przykład zachodniocentrycznej postawy badawczej The Cambridge History of the First World War, reklamowaną wszak jako dzieło, w którym międzynarodowa grupa badaczy ukazuje wojnę w sposób szczegółowy i przekonujący (Spence 2015: 851860). Spojrzenie na listę redaktorów i autorów każe, zdaniem Borodzieja i Górnego, zwątpić w te zapewnienia. Problem wyważenia znaczenia poszczególnych konfliktów dla wojny jako zjawiska globalnego czy to, że nie wszyscy autorzy korzystają $\mathrm{w}$ pełni z najnowszych publikacji dotyczących zagadnień, o których piszą, dostrzegają też niemieccy recenzenci, nie odmawiając jednak dziełu bogactwa wykorzystanego materiału źródłowego ani komparatystycznego podejścia do tematu (Dülffer 2014; Wahl 2014).

Ciekawym zjawiskiem jest sięganie $\mathrm{w}$ zachodnich publikacjach o froncie wschodnim do metod badawczych typowych dla historii militarnej, które zdawały się ostatnio pozostawać na marginesie opracowań dotyczących Wielkiej Wojny, jak chociażby w pierwszej części Die vergessene Front - Der Osten 1914/15 Gerharda P. Großa (2002). Część druga publikacji Schlachtfelder der Vorstellungen - Vorstellung der Schlachtfelder dotyczy natomiast obrazu wroga i doświadczeń żołnierzy, a materiał źródłowy to $\mathrm{w}$ większym stopniu egodokumenty związane z żołnierską codziennością oraz literatura piękna. W tym kontekście szczególnie ciekawy jest tekst Vejasa Gabriela Liuleviciusa, który kreśli związek między okupacyjnymi doświadczeniami Niemców w I wojnie światowej a ich polityką okupacyjną w czasie II wojny (Liulevicius 2002: 295-312; por. Liulevicius 2000), co z kolei wpisuje się w inny ważny nurt badań nad I wojną, a mianowicie umieszczania jej w kontekście ludobójstwa dokonywanego w imię walki o przestrzeń i czystość rasową w ramach polityki kolonialnej, a następnie polityki ludnościowej III Rzeszy (por. m.in. Bergien 2002: 393-408; Zimmerer 2011). Możliwości takiego odczytania Wielkiej Wojny są świadomi także redaktorzy książki Literarische Erinnerung an den Ersten Weltkrieg (Gierlak, KlentakZabłocka und Unger 2017: 8), dochodzi ona najmocniej do głosu w tekście Moniki Tokarzewskiej Der Roman als Schauplatz der Geschichte, w którym powieść historyczna jawi się jako medium czerpiące $\mathrm{z}$ napięcia między tym, co obiektywnie znane, a koniecznością estetycznego przetworzenia danego materiału, medium pozwalające na ogarnianie rozległych przestrzeni i zastosowanie głębokiej perspektywy czasowej. Takie podejście każe $\mathrm{w}$ antysemityzmie czasów I wojny światowej dostrzegać zarzewie późniejszego ludobójstwa (ibid.: 67 i n., 72-74, 76 i n.; por. ibid.: 15).

Nakreślone kierunki badań nad Wielką Wojną - dowartościowanie wpisujących się w I wojnę konfliktów lokalnych, skupienie na historii regionalnej i codzienności ludności cywilnej oraz szeregowych żołnierzy - znajdują swój wyraz we wszystkich tekstach publikacji Literarische Erinnerung. Publikacja składa się z trzech części poprzedzonych wstępem redaktorów tomu, zwięźle zakreślającym obszar zainteresowań autorów poszczególnych publikacji w odniesieniu do kierunków badań nad Wielką Wojną oraz wyraźnie nawiązującym do koncepcji drugiej wojny trzydziestoletniej Hansa-Ulricha Wehlera (2004: 23-35) jako myśli przewodniej książki.

Część pierwsza Regionen in Mitteleuropa podejmuje wymienione wątki badawcze, opowiadając jednak przede wszystkim historie o charakterze regionalnym. Losy ludności cywilnej w Toruniu, prewencyjne działania władz pruskich wymierzone w Polaków mieszkających w mieście (Gierlak, Klentak-Zabłocka und Unger 
2017: 29 i n., 36 i n.), ale też wspólne inicjatywy i działalność organizacji dobroczynnych w tekście Marii Adamiak czy literackie reakcje mieszkańców Prus Wschodnich na wybuch i przebieg wojny, wpisujące się w patriotyczne uniesienie ogółu, a równocześnie świadczące o silnej regionalnej tożsamości autorów w tekście Jensa Stübena (ibid.: 41-64) - dzięki przyjęciu perspektywy oddolnej i uzupełnieniu historii zapisanej w oficjalnych obwieszczeniach władz o zapiski prasowe, wspomnienia i utwory poetyckie malują obraz wojny zwykłych ludzi i świat wprawdzie zmieniony przez wojnę, ale równocześnie ludzki i dlatego bardziej heterogeniczny niż zazwyczaj przedstawiany $\mathrm{w}$ kontekście badań nad I wojną światową. W świecie zwykłych ludzi, na rubieżach zachodniej kultury znajdują się też bohaterowie powieści i opowiadań analizowanych przez Monikę Tokarzewską i Katarzynę Szczerbowską-Prusevicius (ibid.: 85-101). Ludność zróżnicowanych etnicznie Litwy i północno-wschodniej Polski czy bezimienni szeregowi żołnierze chorwaccy odgrywają los wszystkich tych, którzy w opracowaniach dotyczących wojen są kolejnymi numerami w rubrykach wyliczających zabitych i rannych. Równocześnie ukazana przez Mackiewicza, Zweiga i Krležę wielonarodowość północnego wschodu i Bałkanów, niemiecko-żydowskie sąsiedztwo w Magdeburgu czasów wojny i międzywojennych w powieści Schwarz-braun ist die Haselnu $\beta$ Nomi Rubel czy wspólistnienie białych i czarnych mieszkańców Niemieckiej Afryki Wschodniej w pierwszej części Stachel des Skorpions Inge Meyer - zdają się zarzewiem konfliktów, których bynajmniej nie zakończą traktaty pokojowe. Autorki dwóch powieści analizowanych przez Dagmar Ende w tekście Krieg und Nachkrieg in Familiengeschichten nie stawiają krainie dzieciństwa swojego czy swoich rodziców pomnika bez skazy, a ra- czej ten czas odczarowują. Nawet nadzieja na pokonanie zła wraz ze zjednoczeniem Niemiec nie jest niezachwiana.

Teksty pierwszej części książki Literarische Erinnerung czerpią z koncepcji drugiej wojny trzydziestoletniej $\mathrm{w}$ ujęciu Ulricha Wehlera (2004: 23-35) czy z owej wielkiej, brzemiennej w skutkach katastrofy Georga F. Keenana (1979: 3; problematyka Wielkiej Wojny jako katastrofy zob. Jahraus und Kirchmeier 2014), każąc w Wielkiej Wojnie widzieć całkowitą przemianę znanego ludzkości świata i równocześnie podkreślając związek między konfliktami zbrojnymi XX wieku. Takie ujęcie pozwala równocześnie dostrzec $\mathrm{w}$ wojnie cezurę o kluczowym znaczeniu dla budowania europejskiej tożsamości i nie umniejszyć jednostkowych doświadczeń lokalnych konfliktów wpisujących się $\mathrm{w}$ doświadczenie wszechogarniającej katastrofy.

Teksty zamieszczone w części drugiej Zum Spannungsfeld von Region und Nation: Juden, Deutsche, Polen koncentrują się na tematyce wspólistnienia $\mathrm{w}$ wielonarodowych regionach dotkniętych przez działania wojenne, w centrum zainteresowań autorów znajduje się kultura żydowska na Wschodzie. Iwona Kotelnicka-Grzybowska w Zwei Berichte aus dem Osten - Kriegstourismus und Propaganda zabiera czytelnika w podróż na front wschodni, gdzie sprawozdawcy wojenni Fritz Wertheimer (1915), Herbert Eulenberg i Hermann Struck (1916) próbują oswoić obcych sobie ludzi i krajobrazy, sięgając do znanych sobie stereotypów. Choć zdarza im się wychodzić poza utarte poglądy na opisywane ziemie i ludność, to jednak najczęściej okazuje się, że konfrontacja z obcym wcale nie prowadzi do otwarcia się na nowe doznania, a raczej do jeszcze większego zamknięcia się w ciasnych ramach własnej wizji świata. Równocześnie nie można zapomnieć, że na opinie formułowane przez sprawozdawców znaczący wpływ 
miała cenzura (Gierlak, Klentak-Zabłocka und Unger 2017: 138). Szerszą perspektywę na sytuację opisywaną przez Wertheimera, Eulenberga i Strucka prezentuje przywołany przez badaczkę Sammy Gronemann, autor nieco innego spojrzenia (Gronemann 1924) na kwestię wschodnioeuropejskich Żydów. Rozważania Kotelnickiej uzupełnia materiał ilustracyjny, który nie jest tylko dodatkiem, ale stanowi źródło pod względem interpretacyjnym równie ważne jak analizowane teksty. Sammy Gronemann, którego wspomnienia oferują ironiczny komentarz do wydarzeń człowieka stojącego równocześnie w ich samym środku i z boku, przywołuje w Der Erste Weltkrieg und die Nationalitätenfrage także Karol Sauerland wschodnioeuropejscy Żydzi i Huculi jawią się jako obiekt niemieckiej polityki i rozważań intelektualistów, jednostki stojące między frontami i narodami, są wpisani w kontekst wojny przez siły i grupy od nich silniejsze i zainteresowane ich losem tylko jako pionka w globalnej grze o wpływy. Wydarzenia opisywane w Soli ziemi Józefa Wittlina postrzega autor jako element konfliktu rozpoczętego na długo przed zamachem w Sarajewie i bynajmniej nie zakończonego wraz $\mathrm{z}$ rozejmem $\mathrm{w}$ Compiègne. Konflikt i poczucie kryzysu determinują też twórczość Uriego Cwi Grinberga i Abrahama Mosze Fuksa, których literacki rozwój rozpoczyna się w Galicji, a ich świat przeobraża się nie do poznania $\mathrm{w}$ czasie Wielkiej Wojny, co odciska swoje piętno na ich twórczości, każąc szukać środków wyrazu poza naturalizmem i neoromantyzmem. Poszukiwanie własnego głosu, zdolnego oddać sprawiedliwość doświadczeniu zachwiania znanego porządku, oraz refleksja nad możliwością asymilacji Żydów w otaczającym ich świecie są obecne nie tylko w analizie twórczości Grinberga i Fuksa prezentowanych w tekście Armina Eidherra (Gierlak, Klentak-Zabłocka und Unger
2017: 165-177), ale także w twórczości Ernsta Tollera (Die Wandlung), będącej tematem tekstu Thorstena Ungera Die Zerschlagung der Integrationshoffnung des jüdischen Kriegsfreiwilligen in Ernst Tollers "Die Wandlung".

Bardzo płynne jest przejście od tematyki części drugiej publikacji Literarische Erinnerung do części trzeciej kładącej nacisk na Narrationen zwischen allgemeinem und individuellem Kriegserlebnis. Teksty Jürgena Nellesa, Piotra Hęćki, Tomasza Waszaka i Heike Steinhorst to nowe odczytania znanych dzieł literatury oraz utworów prawie nieznanych i rzadko będących obiektem badań. Wanderer zwischen beiden Welten Waltera Flexa w ujęciu Nellesa okazuje się bardziej zróżnicowanym utworem pod względem prezentowanej $\mathrm{w}$ nim interpretacji wojny niż interpretacje współczesnych autora, analiza scen walki wręcz w In Stahlgewittern Ernsta Jüngera i Im Westen nichts Neues Ericha Marii Remarque'a dokonana przez Piotra Hęćkę pozwala na wysnucie ciekawych wniosków dotyczących postaw pro- lub antywojennych autorów, okultystyczne (czy raczej deterministyczne) wizje Gustava Meyrinka w tekście Tomasza Waszaka nabierają wydźwięku pasywnego poddania się siłom wyższym, znajdującym się całkowicie poza obszarem wpływu zwykłego człowieka, a równocześnie oferujące mu drogę „duchowej suwerenności" (ibid.: 253) jako sposób na odnalezienie się w wojennej zawierusze, u Heike Steinhorst - Davos z Czarodziejskiej Góry staje się odbiciem świata odmiennych interpretacji wojny, a proces twórczy Thomasa Manna świadectwem jego wizji tego zbrojnego konfliktu.

Zamykający książkę tekst Thorstena Ungera podejmuje wątki rozsiane $\mathrm{w}$ całej omawianej publikacji. Tożsamość jednostki wobec tożsamości zbiorowej, wielonarodowość w obliczu postulowanej w czasie woj- 
ny wierności ideałom wiodącej kultury z konieczności zostają wprzęgnięte $\mathrm{w}$ taką politykę pamięci, która wielość poświęca na rzecz jedności. Serie wydawnicze czasów Wielkiej Wojny („Österreichische Bibliothek”, „Heimatbücher für deutsche Kriegsgefangene”, „Zeitbücher”) jako medium kształtujące obraz przeszłości państw wielonarodowych i narzędzie polityki historycznej oraz rola miejsc pamięci - wątki obecne także w tekście Jensa Stübena (ibid.: 51, 59) - to zarazem nawiązanie do kolejnego ważnego nurtu badań nad I wojną światową i zagadnienie bardzo współczesne (nakreślenie stanu badań zob. Borodziej i Górny 2015: 150-152; oraz rozdział Die Gedenkkultur des Ersten Weltkrieges w Groß 2002: 313-392; ponadto Verdun jako miejsce pamięci zob. Thiemeyer 2007: 685 i n.). Nieprzypadkowo Unger kończy swój wywód rozważaniami nad przyszłością wizji narodu $\mathrm{w}$ Europie i niebezpieczeństwami wynikającymi z jej powrotu w kształcie, wydawałoby się, dawno już zarzuconym. W tym kontekście nawet rozważania filologa nie mogą ustrzec się od refleksji nad współczesną polityką pamięci i tożsamością narodową, motywem stale powracającym w dyskusji nad Wielką Wojną. Sposób, w jaki wspomina się ten konflikt, mówi bardzo wiele nie tylko o stanie historiografii danego kraju, ale także o mentalności państw europejskich. Rozważania szczegółowe, jak te zaprezentowane $\mathrm{w}$ książce Literarische Erinnerung, są ważne, jeśli pozwalają na wysnucie wniosków o charakterze ogólnym i prezentują wojnę o wielu twarzach, ale nie zacierają obrazu całości, a jedynie go wzbogacają. To, jak sądzę, w omawianej publikacji się udało.
Bibliografia

Bergien, Rüdiger 2002. „Vorspiel des 'Vernichtungskrieges'? Die Ostfront des Ersten Weltkrieges und das Kontinuitätsproblem". W: Gerhard P. Groß (red.). Die vergessene Front Der Osten 1914/15. Ereignis, Wirkung, Nachwirkung. Padeborn-MonachiumWiedeń: Ferdinand Schöningh.

Borodziej, Włodzimierz i Maciej Górny 2015. „Nowsze badania nad I wojną światową w Europie Środkowo-Wschodniej i Południowo-Wschodniej (wybrane zagadnienia)". Kwartalnik Historyczny 1: 131-152.

Dülffer, Jost 2014. „Die geplante Erinnerung. The History Boom Surrounding WWI". https://www.eurozine.com/die-geplante-erinnerung/ [20.03.2018].

Gierlak, Maria, Małgorzata Klentak-Zabłocka und Thorsten Unger (red.) 2017. Literarische Erinnerung an den Ersten Weltkrieg in Regionen Mitteleuropas. Peter Lang: Frankfurt am Main.

Gronemann, Sammy 1924. Hawdoloh und Zapfenstreich. Erinnerungen an die ostjüdische Etappe 1916-1918. Berlin: Jüdischer Verlag.

Groß, Gerhard P. 2002. Die vergessene Front Der Osten 1914/15. Ereignis, Wirkung, Nachwirkung. Padeborn-MonachiumWiedeń: Ferdinand Schöningh.

Hirschfeld, Gerhard, Gerd Krumeich und Irina Renz (red.) 2006. Die Deutschen an der Somme 1914-1918. Krieg, Besatzung, Verbrannte Erde. Essen: Klartext Verlag.

Horne, John und Alan Kramer 2004. Deutsche Kriegsgreuel 1914. Die umstrittene Wahrheit. Thumaczenie Udo Rennert. Hamburg: Verlag des Hamburger Instituts für Sozialforschung.

Jahraus, Oliver und Christian Kirchmeier 2014. „Der Erste Weltkrieg als 'Katastrophe'. Herkunft, Bedeutungen und Funktionen einer problematischen Metapher". http://literaturkritik.de/ $\mathrm{id} / 18875$ [31.01.2018]. 
Keegan, John 1999. The First World War. Nowy Jork: A. Knopf.

Kennan, George Frost 1979. The Decline of Bismarck's European Order. FrancoRussian Relations, 1875-1890. Princeton: Princeton University Press.

Liulevicius, Vejas Gabriel 2000. War Land on the Eastern Front: Culture, National Identity and German Occupation in the World War I. Cambridge: Cambridge University Press.

- 2002. „Von 'Ober Ost' nach 'Ostland'?”. W: Gerhard P. Groß (red.). Die vergessene Front - Der Osten 1914/15. Ereignis, Wirkung, Nachwirkung. Padeborn-Monachium-Wiedeń: Ferdinand Schöningh.

Mick, Christoph 2010. Kriegserfahrungen in einer multiethnischhen Stadt: Lemberg 1914-1947. Wiesbaden: Harrassowitz Verlag.

Pollmann, Ferenc 2013. „Die Ostfront des 'Großen Krieges' - aus ungarischer Perspektive". W: Bernhard Bachinger und Wolfram Dornik (red.). Jenseits des Schützengrabens. Der Erste Weltkrieg im Osten: Erfahrung - Wahrnehmung Kontext. Innsbruck: Studien Verlag.

Spence, John Edward 2015. „The Cambridge History of the First World War". International Affairs 91: 851-860.

Struck, Hermann und Herbert Eulenberg 1916. Skizzen aus Litauen, Weissrussland und
Kurland. 60 Steinzeichnungen mit Text. Berlin: Georg Stilke.

Thiemeyer, Guido 2007. „Der Erste Weltkrieg. Ein Forschungsbericht". Archiv für Sozialgeschichte 47: 683-694.

Wahl, Hans Rudolf 2014. „Neuere Gesamtdarstellungen des Ersten Weltkriegs". https://www.hsozkult.de/publicationreview/id/rezbuecher-22260 [29.03.2018].

Wehler, Hans-Ulrich 2004. „Der zweite Dreißigjährige Krieg, Der Erste Weltkrieg als Auftakt und Vorbild für den Zweiten Weltkrieg". W: Stephan Burgdorff und Klaus Wiegrefe (red.). Der Erste Weltkrieg. Die Urkatastrophe des 20. Jahrhunderts. Monachium: Deutsche Verlags-Anstalt.

Wertheimer, Fritz 1915. Im polnischen Winterfeldzug mit der Armee Mackensen. Mit 40 photographischen Aufnahmen und einem Umschlagbild von Ludwig Putz. Stuttgart-Berlin: Deutsche Verlags-Anstalt.

Zimmerer, Jürgen 2011. Von Windhuk nach Auschwitz? Beiträge zum Verhältnis von Kolonialismus und Holocaust. Münster: LITVerlag 2011.

1914-1918-online. International Encyclopedia of the First World War. http://www.1914-1918-online.net [31.01.2018]. 